\title{
Evaluation of Conspecific Attraction as a Management Tool across Several Species of Anurans
}

\author{
Valerie L. Buxton ${ }^{1}$, Michael P. Ward ${ }^{1,2}$ and Jinelle H. Sperry ${ }^{1,3, *}$ \\ 1 Department of Natural Resources and Environmental Sciences, University of Illinois, 1102 S. Goodwin \\ Avenue, Urbana, IL 61801, USA; vbuxton2@illinois.edu (V.L.B.); mpward@illinois.edu (M.P.W.) \\ 2 Illinois Natural History Survey, University of Illinois, 1816 S. Oak Street, Champaign, IL 61802, USA \\ 3 Engineer Research and Development Center, P.O. Box 9005, Champaign, IL 61826, USA \\ * Correspondence: vbuxton2@illinois.edu; Tel.: +1-217-265-6242
}

Received: 19 December 2017; Accepted: 18 January 2018; Published: 22 January 2018

\begin{abstract}
Amphibian populations are declining worldwide, with habitat loss and alteration being a primary driver of many declines. Management strategies to mitigate these declines include translocation and creation or restoration of breeding habitats, yet these techniques are not always effective. We examined whether conspecific attraction-a management tool frequently used in avian conservation-would be similarly valuable in management and conservation of anuran amphibians (i.e., frogs and toads). We broadcast conspecific chorus sounds at unoccupied, artificial breeding ponds for six anuran species across three field sites. We documented when frogs arrived at each pool and when eggs were laid. We compared differences in number of pools found with adults and egg masses between playback and control pools and examined latency to first colonization. We found that Mexican spadefoots colonized playback ponds faster and more often than control ponds, while Cope's gray treefrogs, Arizona treefrogs, green frogs, spring peepers, and wood frogs exhibited weak or non-existent responses. We discuss why breeding ecology may influence tendency to exhibit conspecific attraction and how this behavior could be used in amphibian management and conservation.
\end{abstract}

Keywords: anurans; conspecific attraction; management; colonization

\section{Introduction}

Amphibians are considered the most imperiled vertebrate group, with $41 \%$ of species described as threatened by the IUCN Red List [1]. In the United States alone, site occupancy of amphibian species listed as threatened by the IUCN declined annually by $11.6 \%$ from 2002 to 2011, and even species listed as of least concern declined by $2.7 \%$ over the same time period [2]. The causes of these declines are multi-faceted, but include disease, climate change, invasive species, and habitat loss and alteration [3-5]. Strategies to mitigate these declines depend on a variety of factors, but may include translocation of individuals to establish new or augment existing populations [6] and the creation and restoration of breeding habitats [7]. Unfortunately, translocation attempts frequently fail [6], and newly created or restored breeding habitats may go undiscovered by target species [8]. Thus, there is a need for new management strategies and conservation tools for amphibians.

Conspecific attraction is one management technique that has been met with success in a variety of avian species [9] and may be similarly applicable to amphibians. Conspecific attraction relies on the premise that individuals use conspecific presence when determining where to settle, resulting in individuals of the same species settling near each other [10-12]. By deploying conspecific cues such as decoys or recordings in unoccupied but suitable areas, researchers have found that they can attract individuals to settle and breed in these areas [9]. While this technique was originally employed to re-establish breeding populations of colonial-nesting waterbirds [13], it has since been 
tested in numerous avian species and is considered a viable tool for the conservation of threatened and endangered songbirds $[9,11]$. Other non-avian species have also been found to use a variety of conspecific cues when selecting habitat: common noctule bats (Nyctalus noctula) use acoustic cues to locate roosts [14], coral reef fish use chemical cues to find reef habitat [15], and bronze anoles (Anolis aeneus) make settlement decisions based on conspecific presence [16]. For amphibians, however, the importance of conspecific cues in the habitat selection process has received little attention and thus the efficacy of conspecific attraction as a conservation tool is largely unknown.

Encouragingly, many temperate anuran amphibian species share characteristics similar to those avian species most likely to exhibit conspecific attraction, including aggregated territories or patchy distributions, a large juvenile to adult ratio, few breeding opportunities, migratory tendencies, and a short or asynchronous breeding season [9]. Indeed, most temperate anurans migrate to centralized locations during their relatively short breeding season where males call to attract females. These calls often propagate at long ranges in the environment [17]. Anurans typically have few opportunities to breed and, when they do, produce large numbers of young. Seemingly, such characteristics might predispose anurans to conspecific attraction and using conspecific calls to locate breeding locations [18], yet field evidence on the topic is scarce [19,20]. Several decades ago, Oldham [21] found that green frogs (Lithobates clamitans) transplanted to a foreign location were more likely to orient toward conspecific calls than were local frogs, and, more recently, James et al. [22] found that conspecific call playbacks influenced the within-pond distributions of green and golden bell frogs (Litoria aurea). Results from laboratory studies have shown that male wood frogs (Lithobates sylvatica), female barking treefrogs (Hyla gratiosa), female gray treefrogs (Hyla versicolor and Hyla chyrsoscelis), and female American toads (Anaxyrus americanus) will all orient toward chorus sounds emanating from a speaker [17,23-25], but limited work has been performed under more natural conditions. In recent field experiments, we found that Cope's gray treefrogs were attracted to artificial ponds using conspecific chorus playbacks, while American toads were not [26]. The prevalence of this attraction behavior in other anuran species is unknown, but if certain species do use conspecific cues to locate breeding habitat, then this technique could potentially be used to enhance colonization at newly created or restored wetlands [26].

Similar to what has been shown with avian species [9], anuran use of cues and efficacy of conspecific attraction as a management tool may potentially vary by characteristics of both the species life history and the environment in which it is found. For example, breeding season length may influence responsiveness, where species with very short breeding windows (i.e., explosive breeders) might use conspecific cues to quickly locate breeding habitat [18]. Breeding pond habitat use may also influence social information use, where species breeding in temporally or spatially unpredictable ponds might be more likely to exploit conspecific cues than those breeding in reliable water bodies (i.e., permanent ponds; 23). Finally, local or regional environmental characteristics might influence conspecific attraction. In dry climates where rainfall occurs sporadically and breeding ponds are scarce, anurans may use conspecific cues to quickly locate suitable habitats and reduce search costs (e.g., desiccation risk, predation risk). Collectively, any of the above factors might interact to influence a species' tendency to use social information and exhibit conspecific attraction.

We experimentally tested for conspecific attraction in six species of anuran amphibians at field sites located in Illinois, Indiana, and Arizona. These species included green frogs, wood frogs, spring peeepers (Pseudacris crucifer), Cope's gray treefrogs, Mexican spadefoots (Spea multiplicata), and Arizona treefrogs (Hyla wrightorum). Selected species occurred in areas with and without significant predictable precipitation and encompassed a variety of life history characteristics and breeding strategies. For each species, we broadcast playbacks of conspecific calls at artificial ponds throughout the breeding season. We monitored subsequent colonization of ponds through surveys for adults and egg masses and determined whether playback ponds were colonized significantly more often than control ponds where no calls were broadcast. 


\section{Materials and Methods}

\subsection{Study Species}

We selected species that encompassed a range of life-history characteristics (Table 1). Cope's gray treefrogs, spring peepers, and green frogs are prolonged breeders, while the remaining species tend to be more explosive in our study areas. Green frogs bred in permanent ponds at our study sites, while the other species bred in a variety of habitats. Arizona treefrogs and Mexican spadefoots are limited to the southwestern United States and Mexico, while the rest of our species are widespread throughout the eastern United States and North America [27].

Table 1. Breeding characteristics of study species. Breeding habitat and period pertain to our particular study sites and do not reflect the variability of each species experienced across wider geographic ranges.

\begin{tabular}{cccc}
\hline Species & Breeding Habitat & Breeding Period & Study Site \\
\hline Hyla chrysoscelis & Seasonal & Prolonged & IL \\
Lithobates clamitans & Permanent & Prolonged & IL \\
Lithobates sylvatica & Seasonal & Explosive & IN \\
Pseudacris crucifer & Ephemeral-Permanent & Prolonged & IL \\
Spea multiplicata & Ephemeral & Explosive & AZ \\
Hyla wrightorum & Permanent $^{\text {a }}$ & Explosive & AZ \\
\hline
\end{tabular}

\subsection{Study Sites and Experimental Design}

\subsubsection{Indiana}

We tested conspecific attraction in wood frogs in 2015 at Camp Atterbury Joint Maneuver Training Center in central Indiana. Similar work was conducted at this site on Cope's gray treefrogs and American toads [26]. The study site was located in a forested area containing several seasonal wetlands that did not contain water year-round, as well as a man-made permanent pond that maintained some water year-round. Auditory surveys in 2014 indicated that wood frogs bred primarily in the seasonal wetlands. For our artificial ponds, we used 18 garden ponds $(1.7 \mathrm{~m} \times 1.2 \mathrm{~m}, 344 \mathrm{~L}$ capacity, Lowe's model \# FPSK91) that had been installed $\geq 140 \mathrm{~m}$ apart from each other in a grid throughout the study site in March 2014 [26]. Distance between ponds was designed to minimize noise contamination among ponds while still reflecting clustering that is often exhibited in constructed wetland systems [7,28,29]. Ponds were flush with the ground and made of flexible polyethelene liner that had two shallow shelves on each side (22.86 cm deep) and a deeper middle $(45.72 \mathrm{~cm}$ deep). Ponds contained leaf litter and branches to encourage algal growth and provide structural support for egg masses.

For the conspecific attraction experiment, we randomly designated ponds as either playback or control. Playbacks consisted of a callbox (FoxPro NX4) broadcasting conspecific vocalizations while controls were silent. Soundtracks of recordings consisted of six different exemplars obtained from publically available or commercial sources (Appendix A, Table A1). Exemplars only contained conspecific calls and consisted of both individual calls and calls of a chorus. Exemplars were normalized to the same peak amplitude using Audacity version 2.0.3. Each exemplar was 2 min long and repeated multiple times on a 60 min track. Callboxes broadcasting playbacks were connected to a timer and deep cycle battery contained within a waterproof plastic bin placed approximately $1.8 \mathrm{~m}$ from the pond. We began broadcasting calls at playback ponds two days prior to the start of natural wood frog breeding activity at the site. Calls were broadcast throughout the day (from 11:00 AM EST to 1:00 AM EST) to correspond with when the species would naturally be calling and at volumes reflecting natural levels. We stopped playbacks after breeding and calling in the surrounding environment had abated. 


\subsubsection{Illinois}

We tested Cope's gray treefrogs and green frogs in 2014 and again tested those two species as well as spring peepers in 2015 at Sparta Training Area in southern Illinois. Ponds were installed in late May 2014 in a grassy matrix with interspersed shrubs surrounded by permanent constructed lakes and ponds that contained water year-round. Because of logistical constraints, eight ponds were placed in the northern section of the site, and the remaining 10 ponds were placed $>1500 \mathrm{~m}$ away in the southern section. Ponds were located in a grid $200 \mathrm{~m}$ apart from each other and were identical to the ponds described above. In 2014, we randomized treatment between northern and southern pond locations and began playbacks for target species despite natural calling and breeding commencement several weeks prior. We jointly targeted gray treefrogs and green frogs using alternating playbacks at treatment ponds during times when species' were naturally calling. We used 4-5 exemplars for each species and broadcast calls for each species for $4 \mathrm{~min}$ before alternating to the other species. We ceased calls in 2014 when natural calling by target species had begun to subside. In 2015, we re-randomized treatment locations and targeted spring peepers beginning in early March using the same methods as above. When the treefrog breeding season was nearing, we switched playbacks to alternating spring peeper/treefrog calls. Later in the spring, we again switched playbacks to alternating treefrog/green frog calls. We did not re-randomize treatment during these switches. Calls were stopped when breeding and calling in the surrounding environment had subsided.

\subsubsection{Arizona}

We tested two species, Arizona treefrogs and Mexican spadefoots, for conspecific attraction in 2016 on United States Forest Service property in southeastern Arizona. Anuran surveys in 2015 confirmed that both of these species were present on the property. We tested treefrogs at Brown Canyon Ranch (BCR), a public use area with two constructed permanent ponds (water was continually pumped into both ponds). We tested spadefoots at a separate site closed to the public (hereafter referred to as "admin site") that contained one constructed ephemeral pond that filled with water during large rainfall events and one constructed permanent pond (water was continually pumped into pond). Both sites consisted of desert grassland and shrubs. In late June 2016, we installed 16 plastic ponds (i.e., child-size wading pools) at BCR and 14 ponds at the admin site. Ponds were located $\geq 70 \mathrm{~m}$ apart from one another and were placed at varying distances from the source pond. Ponds were $1.14 \mathrm{~m}$ in diameter and were filled with approximately $94 \mathrm{~L}$ of water from one of the nearby existing ponds. Because ponds were on the ground rather than flush with the ground, we piled up rocks in two separate locations on the inside and outside of the pond so anurans could enter and exit. We placed sticks and vegetation in ponds for structural support for egg masses. At each site, we randomly designated treatment and control ponds while accounting for distance to nearest natural water source. Prior to the start of the breeding season, we began broadcasting calls for each target species at treatment ponds. Similar to the methods described previously, we used four exemplars for each species (including both commercially available recordings and recordings made by the author VLB at the site in 2015) and broadcast calls at times when each species would naturally be calling.

\subsection{Monitoring and Data Analysis}

To determine the effect of playbacks on anuran behavior, we monitored all ponds every 1-3 d for egg masses and documented presence/absence of eggs. At the Arizona field sites, we relocated any eggs found in our ponds to nearby source breeding pools after counting. We did this because our ponds were small in size and had very limited food resources. Additionally, we considered that high larval densities in pools could deter individuals from breeding in that pool. For certain species, we also conducted visual encounter/auditory surveys beginning within an hour of sunset for evidence of reproductive activity and documented any individuals seen or heard at each pond. Surveys were conducted approximately every third night in Illinois for treefrogs and green frogs. Evening/night 
surveys were conducted less frequently for spring peepers since they bred early in the season and were active during the day. Similarly, wood frogs were active during both the day and night, and thus egg mass surveys and visual encounter/auditory surveys were conducted jointly throughout each day of their short breeding periods. For spadefoots, visual encounter/auditory surveys were conducted after significant rainfall events, as this was when they were most likely to be calling. For logistical reasons, visual encounter/auditory surveys were not conducted for Arizona treefrogs. In Arizona, we randomly placed auditory recorders (Song Meter SM4; Wildlife Acoustics, Inc., Concord, MA, USA) at our experimental ponds (both playbacks and controls) to further determine whether any frog activity was occurring. We removed all heterospecifics found at playback and control ponds and placed them in their nearest natural breeding pond. We also removed conspecifics from control ponds to ensure that silent controls remained silent. We acknowledge that removing conspecifics may bias the number of oviposition events at control ponds and so we present data on both adult colonization and egg mass presence.

To examine the relationship between pond colonization and treatment for both adults and egg masses, we used Fisher's exact tests. For those species that colonized both playback and control ponds, we used a survival analysis and log-rank test to determine whether there was any difference in time to first colonization between treatments. We used logistic regression to determine whether distance to nearest pre-existing breeding wetland influenced colonization probability for adults and egg masses.

\section{Results}

Visual and auditory surveys for adults and egg masses revealed that use of ponds varied by species (Table 2). Results from similar previous work [26] is also presented in Table 2 for comparison purposes. For treefrogs, playback ponds were not colonized by adults significantly more often than control ponds (33\% of playback ponds vs. $11 \%$ of control ponds), and playback ponds were not colonized earlier than control ponds (Figure 1a). Equivalent numbers of playback and control ponds were colonized with egg masses (22\% of each treatment).

For wood frogs, playback ponds were not colonized by adults significantly more often than control ponds (89\% of playback ponds vs. $78 \%$ of control ponds), and playback ponds were not colonized earlier than control ponds (Figure 1b). Slightly more playback ponds were colonized with egg masses than control (67\% of playbacks vs. $44 \%$ of controls), but this difference was not significant, and the first two ponds colonized were control ponds.

For Mexican spadefoots, more playback ponds were colonized by adults than control ponds, but this difference was not statistically significant (71\% of playback ponds vs. $14 \%$ of control ponds. Playback ponds were, however, colonized significantly earlier by adults than the single control pond (Figure 1c). Mexican spadefoots oviposited in only playback ponds, although this difference was not significant (57\% of playback ponds). Throughout the experiment, multiple playback ponds received additional oviposition events. Colonization probability was not associated with distance to nearest existing breeding wetland for adults $(\beta=-0.009, \mathrm{SE}=0.008, p=0.286)$ or egg masses $(\beta=-0.017$, $\mathrm{SE}=0.011, p=0.134)$.

For spring peepers, only one playback pond contained a single frog, with no peeper adults or egg masses observed at any of the other experimental ponds. For Arizona treefrogs, only one playback pond was colonized with egg masses, with no egg masses found at any of the other experimental ponds. No green frog adults or eggs were observed at any of the experimental ponds. 
Table 2. Percentage of playback and control ponds with adults and egg masses observed with a Fisher's Exact Test for significance and a log rank test for difference in latency to first colonization between treatments.

\begin{tabular}{|c|c|c|c|c|c|c|c|c|c|}
\hline \multirow{2}{*}{ Species } & \multirow{2}{*}{ Site } & \multicolumn{2}{|c|}{ Adults Observed } & \multirow{2}{*}{ Fisher's Exact Test } & \multirow{2}{*}{ Latency to Colonization } & \multicolumn{2}{|c|}{ Eggs Observed } & \multirow{2}{*}{ Fisher's Exact Test } & \multirow{2}{*}{ Latency to Colonization } \\
\hline & & \% Playback & $\%$ Control & & & $\%$ Playback & $\%$ Control & & \\
\hline \multirow{2}{*}{ Hyla chrysoscelis } & Indiana $\neq$ & $100(9 / 9)$ & $33(3 / 9)$ & $p=0.009$ & $p=0.001$ & $78(7 / 9)$ & $11(1 / 9)$ & $p=0.015$ & $p=0.005$ \\
\hline & Illinois ${ }^{1}$ & $33(3 / 9)$ & $11(1 / 9)$ & $p=0.578$ & $p=0.259$ & $22(2 / 9)$ & $22(2 / 9)$ & $p=1.000$ & \\
\hline Lithobates clamitans & Indiana & 0 & 0 & & & 0 & 0 & & \\
\hline Lithobates sylvatica & Indiana & $89(8 / 9)$ & $78(7 / 9)$ & $p=1.000$ & $p=0.085$ & $67(6 / 9)$ & $44(4 / 9)$ & $p=0.637$ & $p=0.463$ \\
\hline Pseudacris crucifer & Illinois & $11(1 / 9)$ & 0 & $p=1.000$ & & 0 & 0 & & \\
\hline Spea multiplicata & Arizona & $71(5 / 7)$ & $14(1 / 7)$ & $p=0.103$ & $p=0.040$ & $57(4 / 7)$ & 0 & $p=0.069$ & \\
\hline Hyla wrightorum & Arizona & 0 & 0 & & & $13(1 / 8)$ & 0 & $p=1.000$ & \\
\hline Anaxyrus americanus & Indiana $\neq$ & 0 & 0 & & & 0 & 0 & & \\
\hline
\end{tabular}

${ }^{1}$ Applies only to 2015 experiment. For H. chrysoscelis in 2014, only 1 playback pond was colonized. For L. clamitans in 2014, no ponds were colonized. $\ddagger$ Previously published in Buxton et al. 2015. 


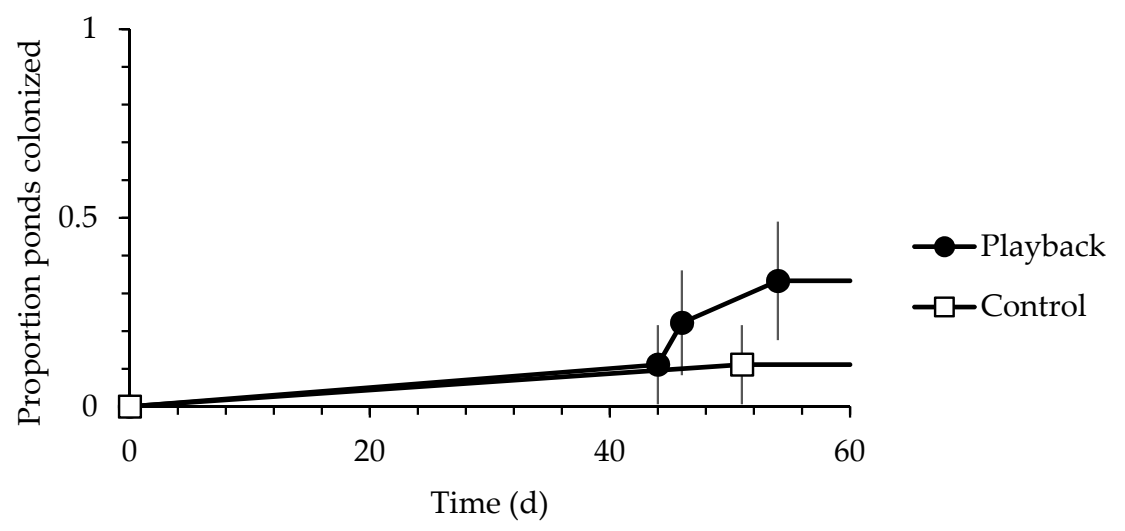

(a)

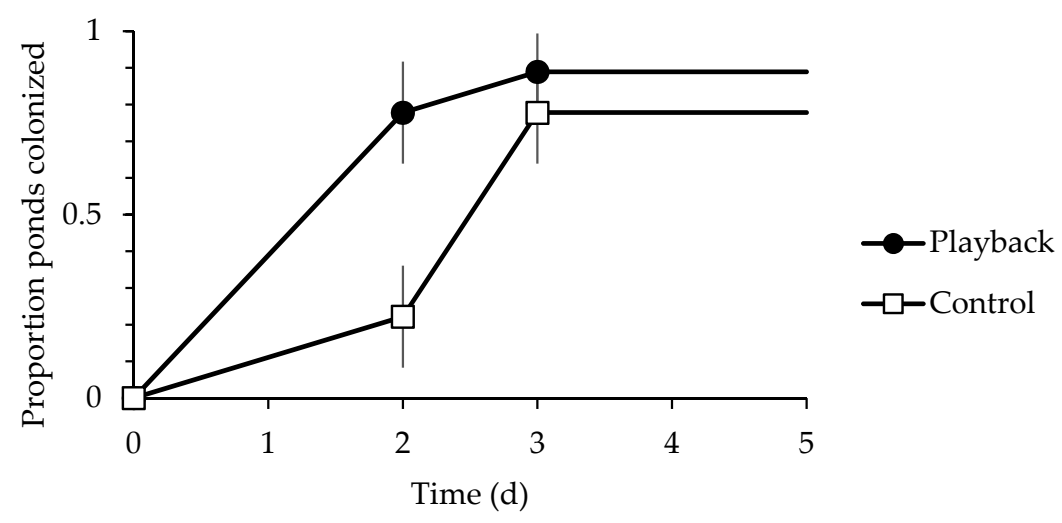

(b)

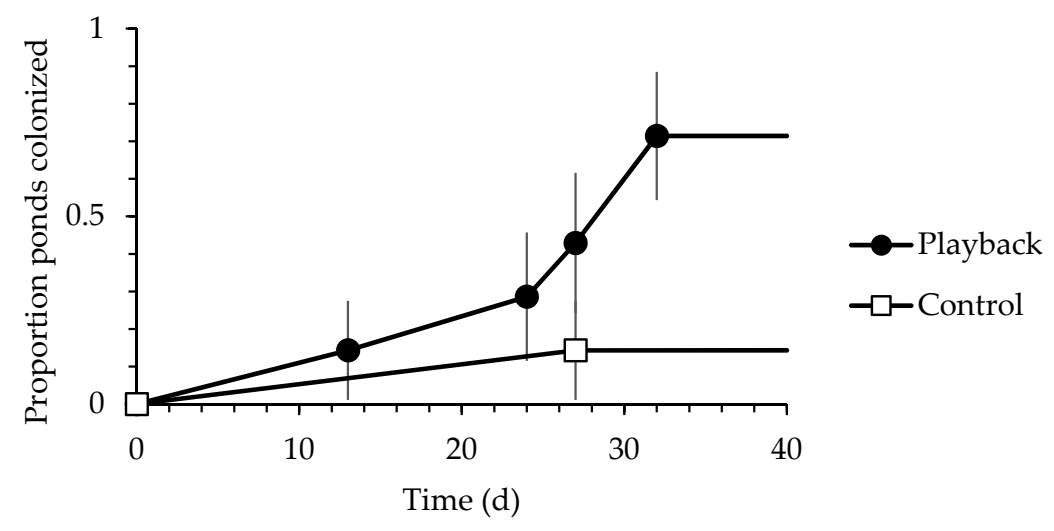

(c)

Figure 1. Colonization curves depicting time (in days) and associated standard errors until first documentation of adults at ponds by treatment for (a) Hyla chrysoscelis in Illinois, 2015; (b) Lithobates sylvatica in Indiana, 2015; and (c) Spea multiplicata in Arizona, 2016.

\section{Discussion}

Our study demonstrates that the efficacy of conspecific attraction for amphibians varies by species. Mexican spadefoots were responsive to playbacks, while response by other species was either weak or nonexistent. Similarly, Buxton et al. [26] found that Cope's gray treefrogs responded to playbacks, while American toads did not. We had expected that differences in responsiveness would be attributed to variation in species breeding ecology, habitat use, and/or landscape characteristics, but we saw few consistent patterns. 
In our study, breeding pond habitat type appeared to influence use of conspecific attraction, with those species using seasonal or ephemeral ponds more likely to respond to playbacks. We saw no use of our experimental ponds by permanent pond breeding green frogs, and Buxton et al. [26] found no use of ponds by American toads, which breed only in permanent ponds in that study area. For most permanent pond breeders, there may be little benefit to using calls to locate alternate breeding areas because they already have personal information on a stable, reliable water source. On the other hand, seasonal and temporary pond breeders, such as Mexican spadefoots, may use calls to locate breeding aggregations that potentially vary unpredictably [23]. Gerhardt and Klump [17] similarly concluded that barking treefrogs responded to conspecific chorus sounds in the laboratory while green treefrogs did not because of their differing breeding habits; barking treefrog aggregations are spatially and temporally unpredictable, while green treefrog aggregations are more stable in space and time. Likewise, avian conspecific attraction studies have found that species using more ephemeral breeding habitats are strongly attracted to pre-breeding season conspecific location cues [30,31].

In addition to habitat use, conspecific attraction may also be influenced by duration of breeding period. While we expected that explosive breeding might select for social information use because individuals need to quickly locate breeding habitat and aggregations [23], we did not see a strong response to playbacks by explosive breeding wood frogs. Similarly, Buxton et al. [26] also did not see a response by explosive breeding American toads. While there appeared to be an initial response to playbacks by adult wood frog migrating to breeding ponds on the first day of breeding activity (almost four times as many playback ponds were found with adults compared to controls), this effect dissipated by the second day. The explanation behind this observation is unclear, but wood frog adults appear to readily colonize new ponds, and the high numbers of wood frogs present at our site may have increased the chances of individuals randomly encountering any of our ponds. Further, conspecific attraction via social cues may be ineffective at high population densities because of increased competition costs [32].

For desert-dwelling species, we expected that orientation toward conspecific calls might be particularly valuable for quickly finding breeding areas in a rather hostile environment. However, only Mexican spadefoots responded to calls, with adults occupying and breeding in over half of the playback ponds. A single spadefoot was remotely detected from auditory recordings at a control pond, but we found no subsequent evidence of breeding in this pond. Interestingly, playbacks appeared to extend the breeding season of spadefoots at the study site, as we observed calling males and breeding activity at our playback ponds even on nights when no natural chorus formed or breeding occurred in the existing temporary pond. The same phenomenon has been observed in bird-voiced treefrogs (Hyla avivoca), where males exposed to playbacks before the onset of the breeding season formed a chorus earlier than in sites without playbacks [33]. While we do not have adult occupancy data for Arizona treefrogs, we found egg masses in only a single playback pond. This pond was one of the playback ponds closest to the source breeding pool (approximately $100 \mathrm{~m}$ away), with a closer control pond located $45 \mathrm{~m}$ from the source pond remaining uncolonized. Because Arizona treefrogs are more desiccation prone and less mobile compared to spadefoots, this may have decreased willingness to engage in exploratory behavior and increased fidelity to the source perennial pool [34].

We consider that little to no colonization in any of our ponds by some of the species tested could be due to factors unrelated to life-history characteristics, such as an aversion to our artificial ponds or inherently low densities at our sites. Regarding the first point, we note that spring peepers breed in a wide variety of habitats [27], and we found egg masses in several of our ponds in subsequent years, suggesting that individuals were not entirely averse to our ponds. Green frogs are probably least likely to breed in our ponds because of the small size of the pond, as a single green frog territory can be larger than our entire pond [35]. Alternatively, lack of a response by green frogs and spring peepers may be due to low abundances of natural aggregations in proximity to our ponds, resulting in decreased likelihood of any individuals entering within perceptual range of our playbacks [36]. 
Low abundance may also have led to lack of colonization by treefrogs in Illinois, as individuals were much more localized at this site and were never heard calling in the northern half of the study area.

An understanding of the role of conspecific cues in the anuran habitat selection process may have important ramifications for conservation and management [22]. If species use conspecific cues to find breeding habitat, newly restored or created ponds may go uncolonized for some time if proper cues are not provided [37]. Consequently, providing conspecific cues may more rapidly facilitate anuran dispersal to new breeding sites and potentially re-establish connectivity among ponds on a larger landscape-level scale [22]. In already occupied areas, chorus sounds may help augment existing population sizes by attracting dispersing individuals, thus better buffering the population against stochastic events [38]. In areas with low-quality breeding habitat (e.g., sites where predatory fish have invaded) or population sinks, conspecific cues could be used to attract individuals to nearby, higher-quality sites. In addition to spatially shifting breeding distributions, calls may also be used to temporally shift a species' breeding period. Indeed, spadefoot calls in our experiment appeared to both stimulate earlier breeding and extend the spadefoot breeding period. Influencing anuran spatial and temporal breeding dynamics in such a manner may ultimately increase reproductive output and probability of egg and tadpole survival and thereby increase population size.

While playbacks may be a useful management tool for certain species, there are a number of potential issues that must be considered. Importantly, potential playback areas should be carefully vetted for quality so that individuals are not attracted to ecological traps [39]. Playbacks may also attract non-target species, including undesirable competitors, predators, or parasites [40,41]. While we did not see any noticeable response by heterospecific anurans to playbacks in any of our experiments, heterospecific information use is generally common between species that share some ecologically similar parameter [42]. Additionally, playbacks may attract individuals carrying diseases (e.g., chytrid or ranavirus), thereby further elevating disease risk and transmission at breeding areas. Conspecific attraction may also be ineffective if cues are not broadcasted within a species' perceptual range; thus, managers must consider the distance between source habitats and playback ponds before implementation [43]. Finally, the number of vocalizations (i.e., single individual vs. a chorus of many) on a playback or characteristics of individual calls could influence response and should be tested further. Given all of these considerations, conspecific attraction could be an important tool in establishing and augmenting anuran populations. Other management methods such as translocation can be expensive and prone to failure [44]. Encouraging colonization of new ponds through playbacks, on the other hand, is an inexpensive and non-invasive method of moving animals across the landscape. While conspecific attraction may not be highly effective for all species, it may be a viable technique for some species in an era with few proven management methods for amphibians [44] and unprecedented amphibian declines [45].

Acknowledgments: This work was supported by the Construction Engineering Research Laboratory. We also thank Camp Atterbury Joint Maneuver Training Center, Sparta Training Area, and the United States Forest Service in Hereford, Arizona, for hosting this research. We especially thank Dawn Slack, Mike Peterkin, Anthony Janas, and John Kraft for their assistance in facilitating this research at these locations. Tremendous thanks to Brian Mahan for overseeing all activities at STA. Thanks to Jayson Rabideau for his help in the field. Thanks to Greg and Kate Taylor for accommodating aspects of this research in Indiana.

Author Contributions: All authors assisted in experiment design; V.L.B collected and analyzed data and wrote the manuscript; M.P.W and J.H.S. provided substantial feedback on the manuscript.

Conflicts of Interest: The authors declare no conflict of interest and the founding sponsors had no role in the design of the study; in the collection, analyses, or interpretation of data; in the writing of the manuscript, and in the decision to publish the results. 


\section{Appendix A}

Table A1. Details of each exemplar used in playback recordings, including the source, catalog \# (if obtained from the Macaulay Library), recordist, and general location of the recording.

\begin{tabular}{|c|c|c|c|c|}
\hline Species & Source & Catalog \#a & Recordist & General Location \\
\hline \multirow{5}{*}{ Cope's gray treefrog } & Macaulay Library, Cornell Lab of Ornithology & ML181955 & Carl H. Gerhardt & Chatham County, GA \\
\hline & Macaulay Library, Cornell Lab of Ornithology & ML183617 & Carl H. Gerhardt & Stoddard County, MO \\
\hline & Macaulay Library, Cornell Lab of Ornithology & ML183750 & Carl H. Gerhardt & Chatham County, GA \\
\hline & Macaulay Library, Cornell Lab of Ornithology & ML185098 & Carl H. Gerhardt & Dent County, MO \\
\hline & Macaulay Library, Cornell Lab of Ornithology & ML176296 & Geoffrey A Keller & Brown County, IN \\
\hline \multirow{6}{*}{ Wood frog } & Macaulay Library, Cornell Lab of Ornithology & ML71895 & Martha J. Fischer & Tompkins County, NY \\
\hline & Macaulay Library, Cornell Lab of Ornithology & ML176110 & Geoffrey A. Keller & Brown County, IN \\
\hline & Macaulay Library, Cornell Lab of Ornithology & ML53160 & Steven R. Pantle & Tioga County, NY \\
\hline & Macaulay Library, Cornell Lab of Ornithology & ML130487 & Gregory F. Budney & Tompkins County, NY \\
\hline & The Frogs and Toads of North America Audio CD & NA & Lang Elliott, Carl H. Gerhardt, Carlos Davidson & Unknown \\
\hline & Voices of the Night Audio CD, produced by Cornell Lab of Ornithology & NA & Arthur A. Allen, Peter P. Kellogg & Unknown \\
\hline \multirow{7}{*}{ Spring peeper } & Macaulay Library, Cornell Lab of Ornithology & ML179076 & Carl H. Gerhardt & Chatham County, GA \\
\hline & Macaulay Library, Cornell Lab of Ornithology & ML176100 & Geoffrey A. Keller & Brown County, IN \\
\hline & Macaulay Library, Cornell Lab of Ornithology & ML94243 & Wilbur L. Hershberger & Frederick County, MD \\
\hline & Macaulay Library, Cornell Lab of Ornithology & ML190947 & Randolph S. Little & Morris County, NJ \\
\hline & Macaulay Library, Cornell Lab of Ornithology & ML179061 & Carl H. Gerhardt & Chatham County, GA \\
\hline & Macaulay Library, Cornell Lab of Ornithology & ML136511 & Michael J. Andersen & Tompkins County, NY \\
\hline & Macaulay Library, Cornell Lab of Ornithology & ML94263 & Wilbur L. Hershberger & Berkeley County, WV \\
\hline \multirow{4}{*}{ Green frog } & Macaulay Library, Cornell Lab of Ornithology & ML176143 & Geoffrey A. Keller & Brown County, IN \\
\hline & Macaulay Library, Cornell Lab of Ornithology & ML138552 & Gregory F. Budney & Hamilton County, NY \\
\hline & Macaulay Library, Cornell Lab of Ornithology & ML163335 & Matthew D. Medler & Tompkins County, NY \\
\hline & The Frogs and Toads of North America Audio CD & NA & Lang Elliott, Carl H. Gerhardt, Carlos Davidson & Unknown \\
\hline \multirow{4}{*}{ Mexican spadefoot } & Personal Recording & NA & Valerie L. Buxton & Cochise County, AZ \\
\hline & The Frogs and Toads of North America Audio CD & NA & Lang Elliott, Carl H. Gerhardt, Carlos Davidson & Unknown \\
\hline & Macaulay Library, Cornell Lab of Ornithology & ML193873 & William E. Duellman & Oaxaca, Mexico \\
\hline & Frog and Toad Calls of the Rocky Mountains: Vanishing Voices & NA & Carlos Davidson & Cochise County, AZ \\
\hline \multirow{4}{*}{ Arizona treefrog } & Personal Recording & NA & Valerie L. Buxton & Cochise County, AZ \\
\hline & Californiaherps.com & NA & Gary Nafis & Coconino County, AZ \\
\hline & The Frogs and Toads of North America Audio CD & NA & Lang Elliott, Carl H. Gerhardt, Carlos Davidson & Unknown \\
\hline & Frog and Toad Calls of the Rocky Mountains: Vanishing Voices & NA & Carlos Davidson & Coconino County, AZ \\
\hline
\end{tabular}




\section{References}

1. The IUCN Red List of Threatened Species. Version 2017-2. Available online: www.iucnredlist.org (accessed on 16 October 2017).

2. Adams, M.J.; Miller, D.A.W.; Muths, E.; Corn, P.S.; Grant, E.H.C.; Bailey, L.L.; Fellers, G.M.; Fisher, R.N.; Sadinski, W.J.; Waddle, H. Trends in amphibian occupancy in the United States. PLoS ONE 2013, 8, e64347. [CrossRef] [PubMed]

3. Stuart, S.N.; Chanson, J.S.; Cox, N.A.; Young, B.E.; Rodrigues, A.S.L.; Fischman, D.L.; Waller, R.W. Status and trends of amphibian declines and extinctions worldwide. Science 2004, 306, 1783-1786. [CrossRef] [PubMed]

4. Beebee, T.J.C.; Griffiths, R.A. The amphibian decline crisis: A watershed for conservation biology? Biol. Conserv. 2005, 125, 271-285. [CrossRef]

5. Cushman, C.A. Effects of habitat loss and fragmentation on amphibians: A review and prospectus. Biol. Conserv. 2006, 128, 231-240. [CrossRef]

6. Germano, J.M.; Bishop, P.J. Suitability of amphibians and reptiles for translocation. Conserv. Biol. 2009, 23, 7-15. [CrossRef] [PubMed]

7. Petranka, J.W.; Holbrook, C.T. Wetland restoration for amphibians: Should local sites be designed to support metapopulations or patchy populations? Restor. Ecol. 2006, 14, 404-411. [CrossRef]

8. Lehtinen, R.M.; Galatowitsch, S.M. Colonization of restored wetlands by amphibians in Minnesota. Am. Midl. Nat. 2001, 145, 388-396. [CrossRef]

9. Ahlering, M.A.; Arlt, D.; Betts, M.G.; Fletcher, R.J., Jr.; Nocera, J.J.; Ward, M.P. Research needs and recommendations for the use of conspecific-attraction methods in the conservation of migratory songbirds. Condor 2010, 112, 252-264. [CrossRef]

10. Stamps, J.A. Conspecifics as cues to territory quality: A preference of juvenile lizards (Anolis aeneus) for previously used territories. Am. Nat. 1987, 129, 629-642. [CrossRef]

11. Ward, M.P.; Schlossberg, S. Conspecific attraction and the conservation of territorial songbirds. Conserv. Biol. 2004, 18, 519-525. [CrossRef]

12. Fletcher, R.J., Jr. Emergent properties of conspecific attraction in fragmented landscapes. Am. Nat. 2006, 168, 207-219. [CrossRef] [PubMed]

13. Kress, S. The use of decoys, sound recordings and gull control for re-establishing a tern colony in Maine. Colonial Waterbirds 1983, 6, 185-196. [CrossRef]

14. Furmankiewicz, J.; Ruczński, I.; Urban, R.; Jones, G. Social calls provide tree dwelling bats with information about the location of conspecifics at roosts. Ethology 2011, 117, 480-489. [CrossRef]

15. Lecchini, D.; Shima, J.; Banaigs, B.; Galzin, R. Larval sensory abilities and mechanisms of habitat selection of a coral reef fish during settlement. Oecologia 2005, 143, 326-344. [CrossRef] [PubMed]

16. Stamps, J.A. Conspecific attraction and aggregation in territorial species. Am. Nat. 1988, 131, 329-347. [CrossRef]

17. Gerhardt, H.C.; Klump, G.M. Phonotactic responses and selectivity of barking treefrogs (Hyla gratiosa) to chorus sounds. J. Comp. Physiol. A 1988, 163, 795-802. [CrossRef]

18. Nocera, J.J.; Forbes, G.J.; Giraldeau, L.A. Inadvertent social information in breeding site selection of natal dispersing birds. Proc. R. Soc. Lond. B 2006, 273, 349-355. [CrossRef] [PubMed]

19. Gerhardt, H.C.; Huber, F. Acoustic Communications in Insects and Anurans: Common Problems and Diverse Solutions; University of Chicago Press: Chicago, IL, USA, 2002; ISBN 9780226288338.

20. Gerhardt, H.C.; Bee, M.A. Recognition and localisation of acoustic signals. In Hearing and Sound Communication in Amphibians, Narins, P.M., Feng, A.S., Fay, R.R., Popper, A.N., Eds.; Springer: New York, NY, USA, 2007; pp. 113-146.

21. Oldham, R.S. Orienting mechanisms of the green frog, Rana clamitans. Ecology 1967, 48, 477-491. [CrossRef]

22. James, M.L.; Stockwell, M.P.; Clulow, J.; Clulow, S.; Mahony, M.J. Investigating behavior for conservation goals: Conspecific call playback can be used to alter amphibian distributions within ponds. Biol. Conserv. 2015, 192, 287-293. [CrossRef]

23. Bee, M.A. Selective phonotaxis by male wood frogs (Rana sylvatica) to the sound of a chorus. Behav. Ecol. Sociobiol. 2007, 61, 955-966. [CrossRef]

24. Swanson, E.M.; Tekmen, S.M.; Bee, M.A. Do female frogs exploit inadvertent social information to locate breeding aggregations. Can. J. Zool. 2007, 85, 921-932. [CrossRef] 
25. Christie, K.; Schul, J.; Feng, A.S. Phonotaxis to male's calls embedded within a chorus by female gray treefrogs, Hyla versicolor. J. Comp. Physiol. A 2010, 196, 569-579. [CrossRef] [PubMed]

26. Buxton, V.L.; Ward, M.P.; Sperry, J.H. Use of chorus sounds for location of breeding habitat in 2 species of anuran amphibian. Behav. Ecol. 2015, 26, 1011-1018. [CrossRef]

27. Denton, R.D.; Richter, S.C. Amphibian communities in natural and constructed ridge top wetlands with implications for wetland construction. J. Wildl. Manag. 2013, 77, 886-896. [CrossRef]

28. Dodd, K.C. Frogs of the United States and Canada; John Hopkins University Press: Baltimore, MD, USA, 2013; ISBN 9781421406336.

29. Rannap, R.; Lõhmus, A.; Briggs, L. Restoring ponds for amphibians: A success story. Hydrobiologia 2009, 634, 87-95. [CrossRef]

30. Ward, M.P.; Semel, B.; Jablonski, C.; Deutsch, C.; Giammaria, V.; Miller, S.B.; McGuire, B.M. Consequences of using conspecific attraction in avian conservation: A case study of endangered colonial waterbirds. Waterbirds 2011, 34, 476-480. [CrossRef]

31. Andrews, J.E.; Brawn, J.D.; Ward, M.P. When to use social cues: Conspecific attraction at newly created grasslands. Condor 2015, 117, 297-305. [CrossRef]

32. Fletcher, R.J., Jr. Species interactions and population density mediate the use of social cues for habitat selection. J. Anim. Ecol. 2007, 76, 598-606. [CrossRef] [PubMed]

33. Martínez-Rivera, C.C. Call Timing Interactions, Aggressive Behavior, and the Role of Acoustic Cues in Chorus Formation in Treefrogs. Ph.D. Dissertation, University of Missouri-Columbia, Columbia, MO, USA, 2008.

34. Mims, M.C.; Hauser, L.; Goldberg, C.S.; Olden, J.D. Genetic differentiation, isolation-by-distance, and indications of a metapopulation of the Arizona treefrog (Hyla wrightorum) in an isolated portion of its range. PLoS ONE 2016, 11, e0160655. [CrossRef] [PubMed]

35. Shepard, D.B. Spatial relationships of male green frogs (Rana clamitans) throughout the activity season. Am. Midl. Nat. 2002, 148, 394-400. [CrossRef]

36. Albrecht-Mallinger, D.J.; Bulluck, L.P. Limited evidence for conspecific attraction in a low-density population of a declining songbird, the Golden-winged Warbler (Vermivora chrysoptera). Condor 2016, 118, 451-462. [CrossRef]

37. Ahlering, M.A.; Faaborg, J. Avian habitat management meets conspecific attraction: If you build it, will they come? Auk 2006, 123, 301-312. [CrossRef]

38. Pechmann, J.H.K.; Wilbur, H.M. Putting declining amphibian populations in perspective: Natural fluctuations and human impacts. Herpetologica 1994, 50, 65-84.

39. Virzi, T.; Boulton, R.L.; Davis, M.J.; Gilroy, J.J.; Lockwood, J.L. Effectiveness of artificial song playback on influencing the settlement decisions of an endangered resident grassland passerine. Condor 2012, 114, 846-855. [CrossRef]

40. Diego-Rasilla, F.J.; Luengo, R.M. Heterospecific call recognition and phonotaxis in the orientation behavior of the marbled newt, Triturus marmoratus. Behav. Ecol. Sociobiol. 2004, 55, 556-560. [CrossRef]

41. Trillo, P.A.; Bernal, X.E.; Caldwell, M.S.; Halfwerk, W.H.; Wessel, M.O.; Page, R.A. Collateral damage or a shadow of safety? The effects of signaling heterospecific neighbours on the risks of parasitism and predation. Proc. R. Soc. B 2016, 283, 20160343. [CrossRef] [PubMed]

42. Seppänen, J.; Forsman, J.T.; Mönkkönen, M.; Thomson, R.L. Information use is a process across time, space, and ecology, reaching heterospecifics. Ecology 2007, 88, 1622-1633. [CrossRef]

43. Fletcher, R.J.; Sieving, K.E. Social-information use in heterogeneous landscapes: A prospectus. Condor 2010, 112, 225-234. [CrossRef]

44. Seigel, R.A.; Dodd, C.K., Jr. Translocation of amphibians: Proven management method or experimental technique? Conserv. Biol. 2002, 16, 552-554. [CrossRef]

45. Wake, D.B.; Vredenburg, V.T. Are we in the midst of the sixth mass extinction? A view from the world of amphibians. Proc. Nat. Acad. Sci. USA 2008, 105, 11466-11473. [CrossRef] [PubMed]

(C) 2018 by the authors. Licensee MDPI, Basel, Switzerland. This article is an open access article distributed under the terms and conditions of the Creative Commons Attribution (CC BY) license (http:/ / creativecommons.org/licenses/by/4.0/). 